\title{
A Spanish version of the athens insomnia scale
}

\author{
Juana Gómez-Benito · Cristina Ruiz • \\ Georgina Guilera
}

Accepted: 13 December 2010

(C) Springer Science+Business Media B.V. 2011

\begin{abstract}
Objectives To develop and validate a Spanish version of the Athens Insomnia Scale (AIS).

Methods The AIS is designed to assess sleep difficulty and comprises eight items: the first five refer to the sleep disturbance and the last three to the daytime consequences. Either the full eight-item scale (AIS-8) or the brief form (AIS-5) can be administered. The adaptation used a backtranslation design. The validation process was based on a sample of 323 participants (undergraduates, community sample and psychiatric outpatients), which completed the AIS and other questionnaires: anxiety (BAI), depression (BDI) and psychological well-being (GHQ-12) scales.

Results The internal consistency coefficients for both versions were above 0.80 . The study of dimensionality revealed a single factor with high loadings and a percentage of explained variance above 50\% in both versions. Test-retest reliability was above 0.70 (AIS-5) and over 0.80 (AIS-8) at a one-month interval. The correlation between the AIS and the previously mentioned scales was for both the AIS-5 and the AIS- 8 above 0.40 and 0.50 , respectively.
\end{abstract}

J. Gómez-Benito · G. Guilera

Department of Methodology and Behavioural Sciences,

University of Barcelona, Barcelona, Spain

J. Gómez-Benito · C. Ruiz

Institute for Brain, Cognition and Behavior (IR3C), Barcelona,

Spain

C. Ruiz (ه)

Centro Médico Teknon, Consultorios-Despacho 56, Marquesa

de Vilallonga, 12, 08017 Barcelona, Spain

e-mail: cris.ruiz@terra.es
Conclusion The psychometric properties of both versions of the Spanish form of the AIS demonstrate that the scale is a valid and reliable instrument for the assessment of insomnia in Spanish-speaking populations.

Keywords ICD-10 - Insomnia - Test adaptation · Validity $\cdot$ Assessment

\begin{tabular}{|c|c|}
\hline \multicolumn{2}{|c|}{ Abbreviations } \\
\hline AIS & Athens Insomnia Scale \\
\hline AIS-5 & Athens Insomnia Scale, 5 items \\
\hline AIS-8 & Athens Insomnia Scale, 8 items \\
\hline BAI & Beck Anxiety Inventory \\
\hline BDI & Beck Depression Inventory \\
\hline DSM-IV & $\begin{array}{l}\text { Diagnostic and Statistical Manual of Mental } \\
\text { Disorders, 4th edition }\end{array}$ \\
\hline GHQ-12 & 12-item General Health Questionnaire \\
\hline ICD-10 & $\begin{array}{l}\text { International Statistical Classification of } \\
\text { Diseases and Related Health Problems, } \\
\text { 10th edition }\end{array}$ \\
\hline ICSD & International Classification of Sleep Disorders \\
\hline PSQI & Pittsburgh Sleep Quality Index \\
\hline SDQ & Sleep Disorders Questionnaire \\
\hline SSS & Stanford Sleepiness Scale \\
\hline
\end{tabular}

\section{Introduction}

Insomnia is a subjective experience of inadequate sleep and is one of the most frequently reported health complaints. People who suffer from insomnia have more somatic and mental disorders [1], and several studies have found a specific relationship between insomnia and depression and/ or anxiety [2-12]. 
Insomnia is an important problem that has often aroused interest among health professionals because it can have negative repercussions not only for the individual's health but also for his or her social and working life [13-15]. People who suffer from insomnia have more current somatic and mental disorders and more pain complaints than do those without insomnia. They also make significantly greater use of health services and take more days of sick leave [1]. For this reason, it would seem necessary to have appropriate standardized procedures for diagnosing it [16]. However, there are relatively few instruments that take into account the issue of clinical utility and that have adequate psychometric properties.

The Athens Insomnia Scale (AIS) [17] is a self-report questionnaire designed to measure the severity of insomnia based on the diagnostic criteria of the ICD-10 Classification of Mental and Behavioural Disorders [18]. There are two versions of the scale: the AIS- 8 and the AIS-5. The original English version of the AIS [17] shows the following: high discrimination indices; adequate internal consistency; appropriate temporal reliability; and good criterion validity. This scale has also proved to be sensitive to change [19]. The AIS therefore can be regarded as a highly useful instrument in both clinical and research settings.

Given that there are very few validated scales that assess insomnia in the Spanish-speaking population, the aim of this study is to develop and validate a Spanish version of the AIS.

\section{Methods}

\section{Participants}

The sample comprised 323 individuals $(29.8 \%$ men and $70.2 \%$ women) with a mean age of 30.29 ( $\mathrm{SD}=14.15$; range 17-79). Specifically, we recruited 167 psychology undergraduates, 77 psychiatric outpatients, and 79 subjects from a community sample. The undergraduates were studying at the Faculty of Psychology of the University of Barcelona. The psychiatric outpatient group was mainly patients who met criteria on Axis I (particularly anxiety, depression and adjustment disorders) or were non-clinical participants but met some criteria on Axis I without fulfilling the complete diagnostic criteria for a specific disorder. They were attending psychiatric routine visits at the Teknon Medical Centre (Barcelona) and the Parc Taulí Hospital (Sabadell). The 79 participants from the community sample were primary health care patients recruited through general practitioners in a local health centre, and also volunteers recruited by the principal researcher. All the participants who made up the sample answered the
Table 1 Sample characteristics

\begin{tabular}{|c|c|c|c|c|c|}
\hline \multirow[t]{2}{*}{ Sample } & \multirow[t]{2}{*}{$N$} & \multicolumn{2}{|c|}{ Gender (\%) } & \multicolumn{2}{|l|}{ Age } \\
\hline & & Males & Females & Mean (SD) & Range \\
\hline Students & 167 & 21.0 & 79.0 & $20.50(2.73)$ & $17-39$ \\
\hline Psychiatric outpatients & 77 & 50.7 & 49.3 & $40.16(11.75)$ & $19-72$ \\
\hline Community sample & 79 & 28.6 & 71.4 & $43.42(14.73)$ & $20-79$ \\
\hline Total sample & 323 & 29.8 & 70.2 & 30.29 (14.15) & $17-79$ \\
\hline
\end{tabular}

questionnaires voluntarily and had been previously informed as to the nature of the investigation. Table 1 shows the details of the whole sample and its sub-sets.

Instruments

The first five items of AIS- 8 form the AIS- 5 and aims to measure sleep induction, awakenings during the night, final awakening, total sleep duration and general sleep quality. The remaining three items of the AIS- 8 refer to the consequences of insomnia during the following day, specifically, well-being, functional capacity (both physical and mental) and sleepiness. Participants are asked to score each item from 0 (no problem at all) to 3 (very serious problem), if they have experienced any difficulty sleeping at least three times a week during the designated study period (at least 1 month in order to fulfil the ICD-10 diagnostic criteria). The total score of the AIS- 8 therefore ranges from 0 to 24 , while that of the AIS-5 ranges from 0 to 15 .

It is well known that there is a clear correlation between insomnia and mood state and the manifestation of anxiety disorders, as well as repercussions on general health of the individual suffering from this sleep disorder. In order to offer concurrent validity evidences exploring the relationships between sleep difficulties and these theoretically associated variables, the following questionnaires were also administered: the Beck's Depression Inventory [20]; the Beck's Anxiety Inventory [21]; the General Health Questionnaire, 12-item version (GHQ-12) [22]. The Beck Depression Inventory is a 21-item self-report scale assessing symptoms of depression. The BDI has shown good test-retest reliability [23] and concurrent validity for test items [24]. Its Spanish version has also demonstrated good reliability and validity in both non-clinical [25] and clinical [26] samples. The BAI [21] is a 21-item self-report inventory for measuring the severity anxiety in psychiatric and general populations. The BAI was found to have high internal consistency and test-retest reliability and good concurrent and discriminant validity. The Spanish version of the BAI [27] seems to have acceptable psychometric properties as an assessment instrument for anxious symptomatology in the adult Spanish population. The GHQ-12 [22] is a self-reporting rating scale that has been used 
widely to identify individuals with general psychological distress. This instrument has been widely used and validated in different countries [28]. In Spain, Cifre and Salanova (2000) [29] and Sánchez-López and Dresch (2008) [30] have tested its reliability and factorial dimensionality with positive results. These three instruments present appropriate psychometric properties and are widely used to assess depression (BDI), anxiety (BAI) and general psychological well-being (GHQ-12). It is expected to find positive correlations with these measures and the AIS.

Procedure

To ensure equivalence between the original English version and the new Spanish adaptation (see the Spanish version in Appendix A), the back-translation procedure was used. This consists in translating the scale from English into Spanish, then from Spanish back into English and, finally, comparing the agreement between the two English versions (the original and the translated one). This was carried out by two philologists (a native English speaker and a native Spanish speaker) both with extensive knowledge of the Spanish and English languages. Each one made a separate translation. When comparing both English versions, no substantial differences were found, thus the proposed Spanish version of the scale was accepted.

The whole sample described in this section responded voluntarily to the Spanish translation of the AIS, after having been informed of the purpose of the study. Participants were asked to respond to the AIS items according to their experience over the last month prior to the day of test administration.

The AIS was subsequently administered a second time to 28 participants of the undergraduate sample 1 month after the initial testing.

Data analysis

Total AIS scores for the different groups were compared by means of the Mann-Whitney $U$ test. The internal consistency of the AIS was evaluated by computing Cronbach's alpha coefficient, and a discrimination index was also obtained for each of the items. The temporal stability of the scale was assessed by means of the intraclass correlation coefficient (ICC). As regards the dimensional structure of the scale a confirmatory factor analysis was performed. Given the ordinal data analysed, covariance matrices and asymptotic covariance matrices were obtained and the Robust Maximum Likelihood method was used for estimation. Finally, the correlations between the AIS and other scales were assessed by computing Spearman's correlation coefficients.

The analyses were performed using SPSS v. 15, Prelis v. 2.50 and LISREL v. 8.8. Statistical significance was set at $\alpha=.05$.
Table 2 General descriptive data

\begin{tabular}{lrlllll}
\hline Sample & $N$ & \multicolumn{2}{l}{ AIS-5 } & & & AIS-8 \\
\cline { 3 - 4 } \cline { 6 - 7 } & & Mean (SD) & Range & & Mean (SD) & Range \\
\hline Students & 167 & $2.82(2.16)$ & $0-10$ & & $4.83(3.56)$ & $0-15$ \\
Psychiatric patients & 77 & $5.22(3.51)$ & $0-15$ & & $8.12(5.34)$ & $0-23$ \\
Community sample & 79 & $4.22(2.96)$ & $0-14$ & & $6.20(4.30)$ & $0-17$ \\
Total sample & 323 & $3.73(2.91)$ & $0-15$ & & $5.95(4.42)$ & $0-23$ \\
\hline
\end{tabular}

\section{Results}

General descriptive data

Table 2 shows the scores for the different groups considered. Comparison of scores revealed significant differences on the AIS-5 between undergraduates and the other two sub-samples (both $P<.05$ ), but not between the group of patients and the general population $(U=2,562.00, z=$ $-1.71 ; P=.09)$. For the AIS-8, differences were observed between the three sample groups, i.e. undergraduates compared to patients ( $U=4,006.50, z=-4.74 ; P<.05$ ), undergraduates compared to the general population $(U=5,445.00, z=-2.22 ; P<.05)$ and patients compared to the general population $(U=2,468.50, z=-2.04$; $P<.05)$.

Internal consistency and temporal stability

Table 3 shows Cronbach's alpha coefficients for both versions of the AIS, as well as the item discrimination indices, for the whole sample. In both versions, eliminating the item with the lowest discrimination index (sleep induction) did not notably increase the global alpha coefficient of the scale.

When considering the sub-samples, the Cronbach alpha coefficients for the AIS-5 were 0.66, 0.83 and 0.78 for undergraduates, patients and the general population, respectively. The corresponding values for the AIS-8 were higher, being $0.81,0.89$ and 0.86 , respectively. As regards the temporal stability, the ICCs were 0.64 for the AIS-5 and 0.75 for the AIS- 8 .

Dimensional structure and relationships with other variables

In order to examine the structure of the scale, one-dimensionality of both the AIS-5 and the AIS- 8 was tested, as well as bi-dimensionality of the AIS- 8 . To evaluate the fit of the corresponding models, we relied on the preferable combinational rule recommended by $\mathrm{Hu}$ and Bentler [31] when not using a large sample. The application of a cut-off value of 0.96 for Comparative Fit Index (CFI) in combination with a 
Table 3 Item descriptives, item discrimination indices and Cronbach's alpha coefficient

\begin{tabular}{|c|c|c|c|c|c|}
\hline \multirow[t]{2}{*}{ Items } & \multirow[t]{2}{*}{ Mean (SD) } & \multicolumn{2}{|l|}{ AIS-5 } & \multicolumn{2}{|l|}{ AIS-8 } \\
\hline & & $\begin{array}{l}\text { Correlation } \\
\text { item-test }\end{array}$ & $\begin{array}{l}\text { Alpha if } \\
\text { item deleted }\end{array}$ & $\begin{array}{l}\text { Correlation } \\
\text { item-test }\end{array}$ & $\begin{array}{l}\text { Alpha if } \\
\text { item deleted }\end{array}$ \\
\hline Sleep induction & $0.62(0.83)$ & 0.44 & 0.79 & 0.39 & 0.87 \\
\hline Awakenings during the night & $0.83(0.79)$ & 0.61 & 0.73 & 0.59 & 0.84 \\
\hline Final awakening & $0.64(0.76)$ & 0.52 & 0.76 & 0.52 & 0.85 \\
\hline Total sleep duration & $0.92(0.78)$ & 0.60 & 0.74 & 0.66 & 0.84 \\
\hline Sleep quality & $0.72(0.80)$ & 0.66 & 0.71 & 0.73 & 0.83 \\
\hline Well-being during the day & $0.73(0.79)$ & & & 0.76 & 0.82 \\
\hline Functioning capacity during the day & $0.60(0.78)$ & & & 0.70 & 0.83 \\
\hline Sleepiness during the day & $0.89(0.70)$ & & & 0.50 & 0.85 \\
\hline Cronbach's alpha & & 0.79 & & 0.86 & \\
\hline
\end{tabular}

cut-off of 0.10 for Standardized Root Mean square Residual (SRMR) resulted in the least sum of Type I and Type II error rates. This rule holds for the models of one-dimensionality of both scales. In fact, the fit of the AIS-5 and AIS- 8 models reaches a CFI value of 0.98 and 0.96 and a SRMR of 0.047 and 0.10 , respectively. In both scales, factor loading between manifest variables and the latent construct were significant different from zero $(P<0.001)$ and standardized value being greater than 0.40 in all cases. Therefore, becoming clear that all the items are relevant to define the global construct. However, the two-factor solution of the AIS-8 produces some unacceptable parameter estimates (Heywood cases), specifically negative error variances. In the model tested, the first five items loaded on the first factor and the final three items loaded on the second factor, according to the theoretical content of the items. It has also been tested the two-factor solution proposed by Yen et al. [32] in which the first factor consists of the first three items and the second factor for the last five. Additionally, with this distribution of items Heywood cases were obtained, which invalidated the model evaluation (Table 4).

The relationships between the AIS and other scales (BDI, BAI and GHQ-12) were explored in the student

Table 4 Factor structure

\begin{tabular}{lll}
\hline Items & AIS-5 & AIS-8 \\
\hline Sleep induction & 0.614 & 0.488 \\
Awakenings during the night & 0.769 & 0.680 \\
Final awakening & 0.702 & 0.623 \\
Total sleep duration & 0.766 & 0.759 \\
Sleep quality & 0.818 & 0.822 \\
Well-being during the day & & 0.858 \\
Functioning capacity during the day & & 0.806 \\
Sleepiness during the day & & 0.628 \\
Eigenvalue & 2.717 & 4.120 \\
Percentage of variance & 54.33 & 51.50 \\
\hline
\end{tabular}

sample. The mean and the standard deviation for the BDI was $7.35(\mathrm{SD}=5.85), 12.71(\mathrm{SD}=8.91)$ for the $\mathrm{BAI}$ and 11.42 ( $\mathrm{SD}=4.89)$ for the GHQ-12. The Cronbach's alpha coefficients were $0.82,0.88$ and 0.86 for the BDI, BAI and GHQ-12, respectively. As would be expected, positive correlations of medium magnitude were obtained between the AIS and the BDI ( 0.46 and 0.53 for the five- and eightitem versions, respectively), between the AIS and the BAI ( 0.42 and 0.49 , respectively), and between the AIS and the GHQ-12 (0.44 and 0.54, respectively).

\section{Discussion}

This study describes the Spanish adaptation of the AIS and reports the main psychometric properties in a sample comprising undergraduates, psychiatric patients and general population. The coefficient of internal consistency obtained for the AIS- 8 was high and quite similar to that reported by Soldatos et al. [17]. The values for temporal stability were also high for both scale samples, although slightly lower than those reported by the Greek authors. This difference may be due to the longer interval used in this study. The analysis confirmed a one-dimensional structure as the most plausible. These results are once again very similar to those obtained by the author's of the original scale [17] and differ from the results obtained by Yen et al. [32]. A possible explanation may be found in the fact that the sample of this study is similar to the sample from Soldatos et al. [17] and different than in Yen et al. [32] who used only adolescent students. More studies are needed to confirm that the factor structure of the AIS- 8 is different between adolescents and adults. The correlations obtained between the AIS and the BDI, BAI and GHQ-12 are consistent with the literature $[5,6,8,33]$ and provide evidence of validity of the AIS. Soldatos et al. [34] conducted a one-day survey on sleep disorders across countries, including Spain. Although the community sample 
in this study had a much higher percentage of women, the mean age was very similar. The percentage of subjects who responded with a 2 or 3 on the AIS was slightly higher than the corresponding percentage in the Soldatos' survey. These differences may partly be due to Soldatos' data being collected by telephone. One noteworthy finding was that in the undergraduate sample, $31.13 \%$ rated at least one item of the AIS-5 as markedly or severely impaired. This percentage is lower than the corresponding figure reported in a Greek study of secondary school pupils [35]. Age and cultural differences could account for this variation.

The results obtained are consistent with the study conducted by Novak et al. [1], who used a Hungarian version of the AIS in their survey of healthcare services use by insomniacs. The scores obtained by Ferentinos et al. [36] were slightly higher than in the present psychiatric sample and more in accordance with those reported by Soldatos et al. [37]; this could be explained by the fact that the former used a population with a main diagnosis of a major depressive disorder and that the AIS scores for the latter were obtained after defining the individuals as insomniacs.

\section{Limitations and future research}

In summary, the AIS is a short, self-report instrument that is both quick and easy to complete, and it can thus be considered as a good screening tool. As with the original scale, the Spanish version has been shown to have good psychometric properties although it is important to take into account the limitations inherent in the samples used, all of which were non-probabilistic. Furthermore, although the Spanish version of the AIS has been validated here with other scales related to insomnia, this study would be enhanced by using either objective measures of sleep (PSG or actigraphy) or other insomnia scales in order to further validate this version. On the other hand, since test-retest reliability was only established using a small undergraduate sample, the stability of the scale should also be confirmed by applying it to larger and more representative samples.

Further research is clearly needed to corroborate the present results and ensure that the scale can reliably be used in the clinical setting. Nevertheless, given that there is no other validated sleep scale of this type in Spain, the data reported here are relevant and constitute an important step forward in this field.

\section{Appendix A}

Spanish version of the Athens Insomnia Scale

\section{Escala de Insomnio de Atenas}

Edad

Sexo:

Fecha:

Instrucciones: Esta escala pretende registrar su propia valoración acerca de cualquier dificultad que

haya podido experimentar. Por favor, responda los siguientes ítems (marcando con un círculo el número apropiado), indicando las dificultades que le hayan ocurrido como mínimo tres veces a la semana durante el último mes.

Inducción del sueño (tiempo que tarda en dormirse después de apagar la luz)

0: Ningún problema 1 : Ligeramente retrasado 2: Marcadamente retrasado 3: Muy retrasado o no durmió

Despertares durante la noche

0: Ningún problema 1: Problema menor 2: Problema considerable 3: Problema serio o no durmió

Despertar final antes de lo deseado

0 : No fue antes $\quad 1$ : Un poco antes $\quad 2$ : Notablemente antes $\quad 3:$ Mucho antes o no durmió 


\section{Duración total del sueño}

0: Suficiente 1: Ligeramente insuficiente 2: Notablemente insuficiente 3: Muy insuficiente o no

durmió

\section{Calidad general del sueño (no importa cuánto tiempo durmió)}

0: Satisfactoria 1: Ligeramente insatisfactoria $\quad$ 2: Notablemente insatisfactoria $\quad 3$ : Muy

insatisfactoria o no durmió

Sensación de bienestar durante el día

0: Normal 1: Ligeramente disminuida 2: Notablemente disminuida 3: Muy disminuida

\section{Funcionamiento (físico y mental) durante el día}

0: Normal 1: Ligeramente disminuido 2: Notablemente disminuido 3: Muy disminuido

\section{Somnolencia durante el día}

0 : Ninguna 1: Moderada 2: Considerable 3: Intensa

El periodo de la auto-administración puede variar, dependiendo del diseño de cada estudio. Cuando la auto-

administración se haya efectuado en un periodo distinto al del mes anterior, la segunda frase de las

instrucciones debería corregirse consecuentemente.

\section{References}

1. Novak, M., Mucsi, I., Shapiro, C. M., Rethelyi, J., \& Kopp, M. S. (2004). Increased utilization of health services by insomniacs-an epidemiological perspective. Journal of Psychosomatic Research, 56(5), 527-536.

2. Soldatos, C. R. (1994). Insomnia in relation to depression and anxiety: Epidemiologic considerations. Journal of Psychosomatic Research, 38(Suppl 1), 3-8.

3. Ford, D. E., \& Kamerow, D. B. (1989). Epidemiologic study of sleep disturbances and psychiatric disorders: An opportunity for prevention? JAMA, 262(11), 1479-1484.

4. Breslau, N., Roth, T., Rosenthal, L., \& Andreski, P. (1996). Sleep disturbance and psychiatric disorders: A longitudinal epidemiological study of young adults. Biological Psychiatry, 39(6), 411-418.

5. American Psychiatric Association. (2000). Diagnostic and statistical manual of mental disorders, 4th edition, text revised (DSM$I V-T R)$. Washington, DC: American Psychiatric Association.

6. Riemann, D., \& Voderholzer, U. (2003). Primary insomnia: A risk factor to develop depression. Journal of Affective Disorders, 76(1-3), 255-259.

7. Chang, P. P., Ford, D. E., Mead, L. A., Cooper-Patrick, L., \& Klag, M. J. (1997). Insomnia in young men and subsequent depression: The johns hopkins precursor study. American Journal of Epidemiology, 146(2), 105-114.

8. Johna, U., Meyera, C., Rumpfb, H. J., \& Hapke, U. (2005). Relationships of psychiatric disorders with sleep duration in an adult general population simple. Journal of Psychiatric Research, 39(6), 577-583.

9. Allgöwer, A., Wardle, J., \& Steptoe, A. (2001). Depressive symptoms, social support, and personal health behaviours in young men and women. Health Psychology, 20(3), 223-227.
10. Gillin, J. C., \& Byerley, W. F. (1990). The diagnosis and management of insomnia. New England Journal of Medicine, 322(4), 239-248.

11. Alapin, I., Fichten, C. S., Libman, E., Creti, L., Bailes, S., \& Wright, J. (2000). How is good and poor sleep in older adults and college students related to daytime sleepiness, fatigue, and ability to concentrate? Journal of Psychosomatic Research, 49(5), 381-390.

12. Morin, C. M., Kowatch, R. A., Barry, T., \& Walton, E. (1993). Cognitive-behaviour therapy for late-life insomnia. Journal of Consulting and Clinical Psychology, 61(1), 137-146.

13. Morin, C. M. (1993). Insomnia: Psychological assessment and management. New York: Guildford Press.

14. Morin, C. M. (2000). The nature of insomnia and the need to refine our diagnostic criteria. Psychosomatic Medicine, 62(4), 483-485.

15. Zammit, G. K., Weiner, J., Damato, N., Sillup, G., \& McMillan, C. H. (1999). Quality of life in people with insomnia. Sleep, 22(Suppl 2), 379-385.

16. Irwin, M. R., Cole, J. C., \& Nicassio, P. M. (2006). Comparative meta-analysis of behavioural interventions for insomnia and their efficacy in middle-aged adults and in older adults 55+ years of age. Health Psychology, 25(1), 3-14.

17. Soldatos, C. R., Dikeos, D. G., \& Paparrigopoulos, T. J. (2000). Athens Insomnia Scale: Validation of an instrument based on ICD10 criteria. Journal of Psychosomatic Research, 48(6), 555-560.

18. World Health Organization. (1992). The ICD-10 classification of mental and behavioral disorders: Diagnostic criteria for research (10th revision). Geneva: World Health Organization.

19. Shen, J., Chung, S. A., Kayumov, L., Moller, H., Hossain, N., Wang, X., et al. (2006). Polysomnographic and symptomatological analyses of major depressive disorder patients treated with Mirtazapine. Canadian Journal of Psychiatry, 51(1), 27-34. 
20. Beck, A. T., Ward, C. H., \& Mendelson, M. (1961). An inventory for measuring depression. Archives of General Psychiatry, 4, 561-571.

21. Beck, A. T., Epstein, N., Brown, G., \& Steer, R. A. (1988). An inventory for measuring clinical anxiety: Psychometric properties. Journal of Consulting and Clinical Psychology, 56(6), 893-897.

22. Goldberg, D., \& Williams, P. (1988). A user's guide to the General Health Questionnaire. Windsor, UK: NFER-Nelson.

23. Beck, A. T., Steer, R., \& Garbin, M. (1988). Psychometric properties of the BDI: Twenty-five years of evaluation. Clinical Psychology Review, 8, 77-100.

24. Reynolds, W. M., \& Gould, J. W. (1981). A psychometric investigation of the standard and short form beck depression inventory. Journal of Consulting and Clinical Psychology, 49(2), 306-307.

25. Sanz, J., \& Vázquez, C. (1998). Fiabilidad, validez y datos normativos del inventario para la depresión de Beck. Psicothema, 10, 303-318.

26. Vazquez, C., \& Sanz, J. (1999). Reliability and validity of the Spanish version of the beck depression inventory (1978) in patients with psychological disorders. Clinica y Salud, 10(1), 59-81.

27. Magan, I., Sanz, J., \& García-Vera, M. P. (2008). Psychometric properties of a Spanish version of the beck anxiety inventory (BAI) in general population. The Spanish Journal of Psychology, 11(2), 626-640.

28. Goldberg, D. P., Gater, R., Sartorius, N., Ustun, T. B., Piccinelli, M., Gureje, O., et al. (1997). The validity of two versions of the GHQ in the WHO study of mental illness in general health care. Psychological Medicine, 27, 191-197.
29. Cifre, E., \& Salanova, M. (2000). Validación factorial del General Health Questionnaire (GHQ-12) mediante un análisis factorial confirmatorio. Revista de Psicología de la Salud, 12(2), 75-89.

30. Sánchez-López, M. P., \& Dresch, V. (2008). The 12-item general health questionnaire: Reliability, external validity and factor structure in the Spanish population. Psicothema, 20(4), 839-843.

31. Hu, L., \& Bentler, P. M. (1999). Cutoff criteria for fit indexes in covariance structure analysis: Conventional criteria versus new alternatives. Structural Equation Modeling, 6(1), 1-55.

32. Yen, C. F., King, B. H., \& Chang, Y. P. (2010). Factor structure of the Athens Insomnia Scale and its associations with demographic characteristics and depression in adolescents. Journal of Sleep Research, 19, 12-18.

33. Hamilton, N. A., Catley, D., \& Karlson, C. (2007). Sleep and affective response to stress and pain. Health Psychology, 26(3), 288-295.

34. Soldatos, C. R., Allaert, F. A., Ohta, T., \& Dikeos, D. G. (2005). How do individuals sleep around the world? Results from a single-day survey in ten countries. Sleep Medicine, 6(1), 5-13.

35. Lazarotou, H., Dikeos, D. G., Anagnostopoulos, D. C., Sbokou, O., \& Soldatos, C. R. (2005). Sleep problems in adolescence. A study of senior high school students in Greece. European Child and Adolescence Psychiatry, 14(4), 237-243.

36. Ferentinos, P., Kontaxakis, V., Havaki-Kontaxaki, B., Paparrigopoulos, T., Dikeos, D., Ktonas, P., et al. (2009). Sleep disturbances in relation to fatigue in major depression. Journal of Psychosomatic Research, 66(1), 37-42.

37. Soldatos, C. R., Dikeos, D. G., \& Paparrigopoulos, T. J. (2003). The diagnostic validity of the athens insomnia scale. Journal of Psychosomatic Research, 55(3), 263-267. 